\title{
Vamos a replicar la vida: Manual de huertos familiares para mentoras del programa Abriendo Oportunidades
}

Population Council

Follow this and additional works at: https://knowledgecommons.popcouncil.org/departments_sbsr-pgy How does access to this work benefit you? Let us know!

\section{Recommended Citation}

"Vamos a replicar la vida: Manual de huertos familiares para mentoras del programa Abriendo Oportunidades." Ciudad de Guatemala: Population Council, 2021. 


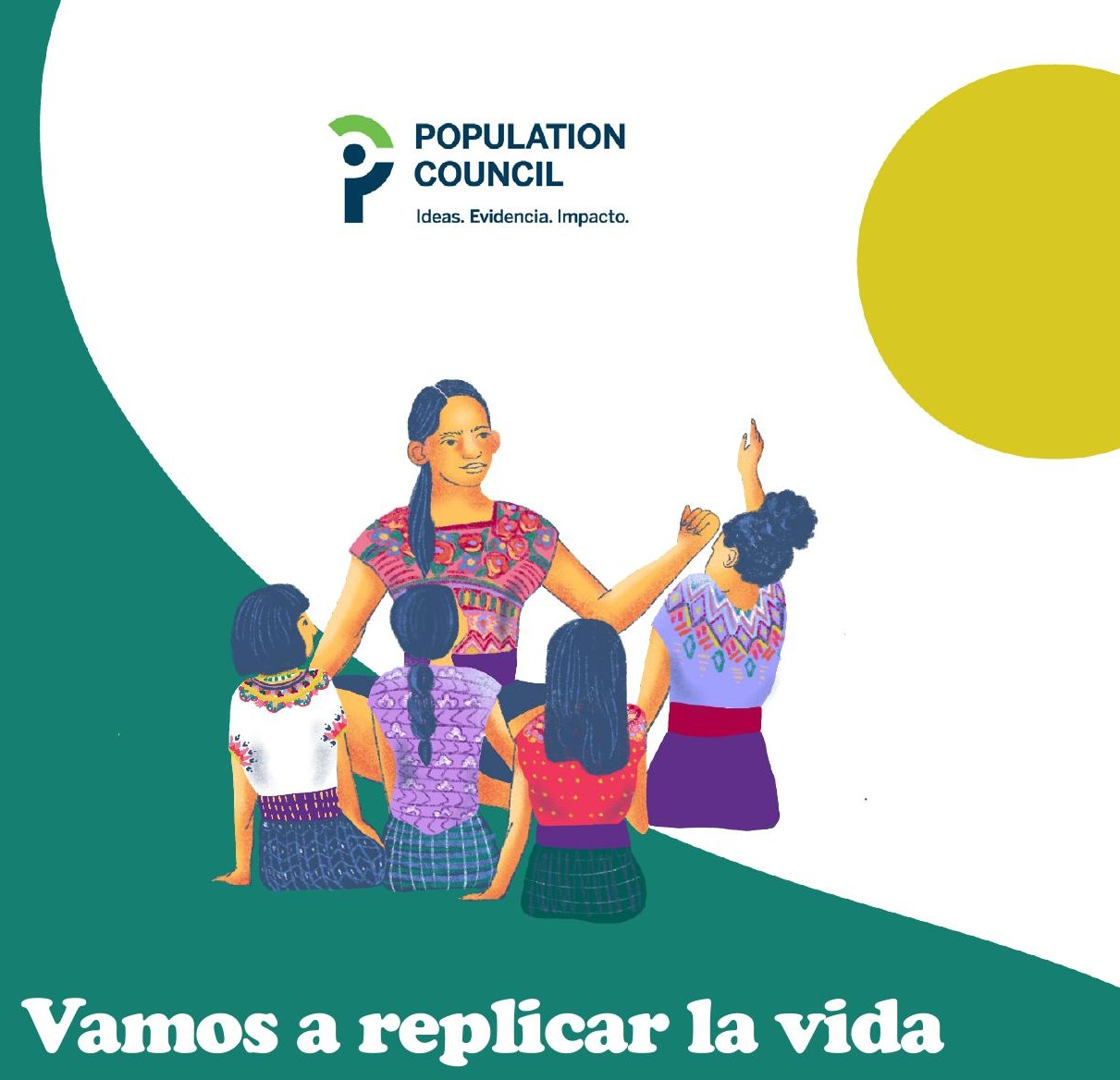

Manual de huertos familiares para mentoras del programa Abriendo Oportunidades ${ }^{\circledR}$ 
El Population Council enfrenta problemas críticos de salud y desarrollo, desde detener la propagación del VIH hasta mejorar la salud sexual reproductiva y garantizar que los jóvenes lleven una vida plena y productiva. A través de la investigación biomédica, de ciencias sociales y de salud pública en 50 países, trabajamos con nuestros socios para ofrecer soluciones que conduzcan a políticas, programas y tecnologías más efectivas que mejoren vidas en todo el mundo. Establecido en 1952 y con sede en Nueva York, el Council es una organización no gubernamental, sin fines de lucro, gobernada por una junta internacional.

\section{Population Council Guatemala}

19 avenida 0-35 Zona 15, Vista Hermosa 2, Ciudad de Guatemala, 01015 Guatemala Tel: +502 2369-0292

popcouncil.org

Insumos de base:

REDMI Aq'ab'al

Texto, diseño y diagramación:

Luis Méndez Salinas y Carmen Lucía Alvarado

Ilustraciones:

Paula Gramajo, Mario Valdez y Leke García

\section{Ciudad de Guatemala, Population Council}

(C) 2020 The Population Council, Inc.

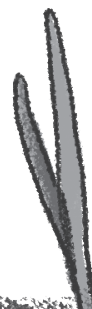




\section{Vamos a replicar la vida}

\section{Manual de huertos familiares para mentoras del programa Abriendo Oportunidades ${ }^{\circledR}$}

Estás a punto de empezar un camino de siete sesiones en el que guiarás a muchas niñas hacia el conocimiento, la soberanía alimentaria y el porvenir. Además de enseñarles a realizar un huerto familiar, contigo aprenderán a preguntar en su comunidad, a imaginar lo que serán en el futuro y a hablar con la tierra.

Esta pequeña guía te ayudará a llevar mejor tus sesiones. Todos sus contenidos serán ampliados y reforzados a través de materiales complementarios que llegarán directamente a tu celular: canciones, textos e imágenes para compartir con tu grupo.

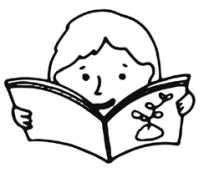

Cada vez que vez que veas esta figura, pon atención a los conceptos que deberás compartir con las niñas.

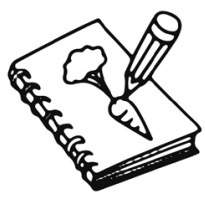

Verás que en cada sesión aparece el dibujo de este pequeño cuaderno. Cuando lo veas, dirige a las niñas a su cuadernillo, ya que en él encontrarán los espacios e indicaciones para realizar alguna actividad.

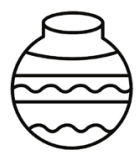

Este dibujo te indicará a ti y a las niñas que es necesario recordar el proyecto que une las siete sesiones: la realización de los dibujos que decorarán sus recipientes para semillas.

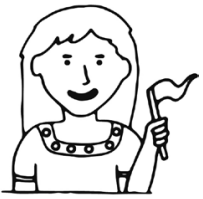

Las tareas y recomendaciones que les darás para la siguiente sesión, se verán representadas por el dibujo de esta mentora. 


\section{Primera sesión}

\section{La diversidad de cultivos}

\section{Querida mentora:}

Antes de iniciar esta primera sesión, debes saludar a las niñas diciéndoles que lo que aprenderán en este espacio seguro será muy importante para sus vidas. Mientras van llegando, pídeles que hagan memoria: que piensen un momento en los cultivos, en la tierra, en todo lo que nace de ella, en lo que nos alimenta; que piensen en lo que se siembra en su entorno inmediato.

Cuando todas hayan llegado, comparte con ellas la energía que rige el día según el calendario ancestral, y luego cuéntales que van a hablar de un tema muy importante para nuestro cuerpo y para la tierra que nos rodea: la diversidad de cultivos. A través de WhatsApp recibirás un calendario de los próximos meses y un breve resumen de las energías de los días. En cada sesión tendrás que buscar la energía correspondiente y compartirla con las niñas.

Ten en cuenta este concepto clave:

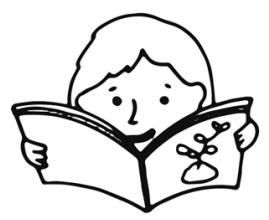

La diversidad de cultivos se refiere a las diferentes siembras que realizan la personas en sus terrenos para obtener productos variados en las diferentes épocas del año. Es fundamental que los seres humanos tengamos diversas siembras para garantizar el bienestar de nuestra familia. 


\section{Replicar la vida}

Pídele a las niñas que vean su entorno: deja que se acerquen a las ventanas y a las puertas, y que pongan atención a lo que ven. La idea de este ejercicio es ubicar todo lo que está cultivado alrededor. En caso de que esos cultivos no se vean de manera inmediata, intenta hacer un recorrido mental por el lugar. Ubica las siembras que más se vean y que sean conocidas por las niñas. Habla de eso con el grupo. Menciona, por ejemplo, la siembra de maíz de un vecino, los árboles frutales de una vecina, el frijol y el ayote que crece cerca. Además, pregúntales ¿̇cuántos cultivos tienen en su casa? ¿̇qué cultivos han sembrado y cosechado ellas?

Lo que las niñas deben comprender es que ese entorno es el que entra en nuestro cuerpo a través de los alimentos, y mientras más variedad de cultivos encuentren a su alrededor, más variedad de nutrientes entra en el cuerpo; esto quiere decir que comemos mejor y pagamos menos, porque todo lo tenemos a mano.

\section{Nunca comemos una sola cosa}

Mientras más variada sea nuestra dieta, es mejor para nuestra salud. Y mientras más variados sean los cultivos, es mejor para la salud de la tierra. Sabiendo esto, debes explicar que los monocultivos (esas grandes extensiones de tierra que solo tienen un tipo de siembra) no son saludables para la tierra, tampoco para el cuerpo, ni para nuestra economía.

Los monocultivos no se dan de manera natural, son artificiales, y todo lo artificial es menos sano. Para que la tierra produzca mucho de una sola especie, se necesita usar químicos, y esos químicos se quedan en la comida, entran a nuestro cuerpo y, aunque no lo sepamos, nos van enfermando. 
Explícales que hay muchas formas de solucionar ese proble$\mathrm{ma}, \mathrm{y}$ por eso es importante tener presente todos los tipos de alimento que la tierra nos puede ofrecer. En este momento debes poner especial atención en que las niñas comprendan la inmensa variedad de comida que existe. Puedes pedirles que cada una diga nombres de alimentos que nacen de la tierra, y apúntalos en un papelógrafo.

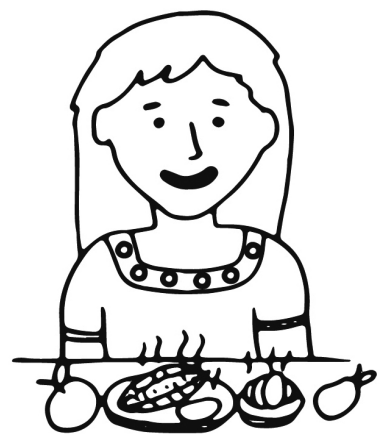

Al tener todos los nombres apuntados, pídeles a las niñas que te ayuden a clasificar todos esos alimentos en estas categorías: semillas, raíces, frutas, flores, hierbas, verduras. Piensen juntas en la variedad de sus sabores y sus formas. Marca cada categoría con un color, para que al terminar vean el papelógrafo lleno de colores.

\section{Hagamos algo juntas}

Los colores que nos alimentan

Después de haber hablado del entorno, y de toda la comida que nos rodea, le

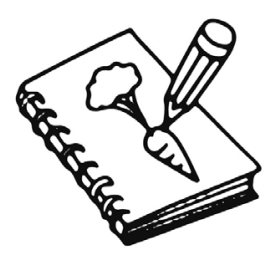
pedirás a las niñas que dibujen el paisaje que habitan, tomando en cuenta todos los espacios en los que nace la comida. En su cuadernillo tendrán dos espacios para dibujar: en el primero irá el paisaje y en el segundo cada niña debe dibujarse a sí misma. 
Cuando los dibujos estén terminados, pídeles que tracen una línea que va desde cada cultivo hacia su boca, utilizando el color distintivo de cada fruta, verdura, grano, flor, etc.

Al terminar esta actividad las niñas tendrán claro que todos los colores simbolizan los nutrientes y la variedad de alimentos que entran a nuestro cuerpo. Esto las hará sentir más vinculadas con la tierra, y sabrán que lo que le pasa a la tierra de alguna forma también nos pasa a nosotras, por lo que es importante variar los alimentos y sembrar distintas plantas.

\section{Un recipiente para guardar nuestras semillas}

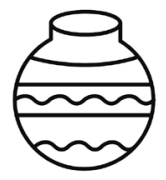

Cuéntales a las niñas que durante las siete sesiones de este ciclo, irán acumulando materiales para crear algo que les será muy útil: un recipiente para guardar las semillas que sembrarán en su huerto familiar. Diles que en ese objeto estará representado todo lo que aprenderán juntas.

Al final de la sesión, pídeles que de camino a casa observen todo y que tengan en mente lo que aprendieron. Solicítales que para la siguiente sesión cada una lleve semillas que encuentren en su casa, que tengan a mano. No necesitarán muchas pero serán importantes para lo que aprenderán la próxima vez que se vean.

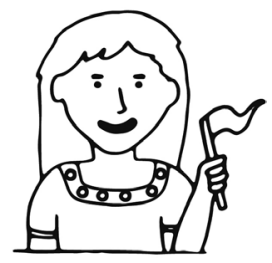




\section{Segunda sesión}

\section{Todo surge de las semillas}

Conforme las niñas vayan llegando, dale la bienvenida a cada una y agradécele que haya regresado porque es muy importante continuar con el proceso de aprendizaje. Al iniciar la sesión recuerda saludarlas contándoles sobre la energía del día que rige según nuestro calendario. De manera breve, resume lo que hablaron la semana anterior y haz un par de preguntas para garantizar que refresquen su memoria.

Ten presentes los siguientes conceptos clave:

Una semilla es aquella parte de una planta ya existente, capaz de ser fuente de la creación de una nueva planta del mismo tipo.

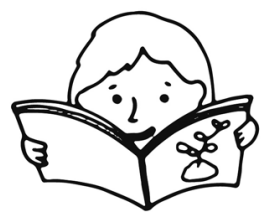

Un embrión es el origen del fruto vegetal se encuentra en la semilla.

La germinación es el proceso mediante el cual un embrión se desarrolla hasta convertirse en una planta. Este es un proceso que se lleva a cabo cuando el embrión se hincha y la cubierta de la semilla se rompe, y sucede debajo de la tierra.

\section{La importancia de las semillas}

El tema de esta segunda sesión es sobre las semillas, y para tratarlo vamos a utilizar una forma sencilla pero muy efectiva de explicar su importancia para la continuidad de la vida. Considerando que las semillas son las que en el futuro darán origen a nuestros alimentos, diles a las niñas que esas semillas son los bebés de nuestra comida. Tienen que entrar a la tierra, porque la tierra es la mamá de todas. Y 
ahí, como un bebé, las semillas crecen y van a salir a la luz cuando estén listas.

Además, pon especial atención en lo pequeñas que son las semillas. Explícales que por más chiquitas que sean, adentro van plantas, frutas, verduras, raíces; solamente necesitan el cuidado adecuado, y el tiempo suficiente para que pronto se conviertan en el alimento que nos nutre, nos da fuerza, y nos hace sentir y pensar.

Luego de esta explicación, pregúntales qué semillas trajeron y pídeles que las saquen. Tomando en cuenta lo que les acabas de explicar sobre todo lo que contienen las semillas, toma una y diles todo lo que esa semilla tiene dentro. Para ayudarte te pondremos estos ejemplos:

Un grano de maíz: lleva dentro un maizal, una milpa, muchas mazorcas que luego se convertirán en masa, y después en tamalitos, tortillas, atoles.

Una semilla de ayote se convertirá después en los ayotes que crecen con el maíz, y que serán grandes y de distintos colores: verdes, amarillos, anaranjados; y cuando estén listos, podremos comer esos ayotes en caldos, en dulces, tostaremos algunas de sus semillas y las moleremos para hacer recados.

Con estos ejemplos pídeles que expliquen todo lo que llevan dentro las semillas que llevaron.

\section{Hagamos algo juntas}

El paso de la semilla al alimento

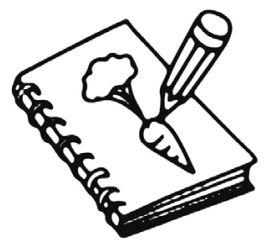

En su cuadernillo, cada niña encontrará un cuadro con tres columnas. En la primera columna deben dibujar sus semillas, en la segunda harán un dibujo de 
los cultivos que crecerán de esa semilla, y en la tercera deberán escribir una lista de las comidas que podrán hacer cuando cosechen esos cultivos.

\section{E1 tiempo y la tierra trabajan juntos}

Ahora debes hablarles de la tierra y del tiempo, dos elementos esenciales para que las semillas germinen y empiecen su camino hasta convertirse en nuestro alimento. La preparación de la tierra y el conocimiento que debes tener sobre las fases de la luna, los días que se necesitan y los cuidados específicos deben quedar claros para que las niñas puedan poner en práctica lo que aprendan. Debes explicarles sobre los días de germinación que se necesitan dependiendo del tipo de semilla, el tiempo que se cuida el cultivo y la cantidad de trabajo y esfuerzo que se requiere.
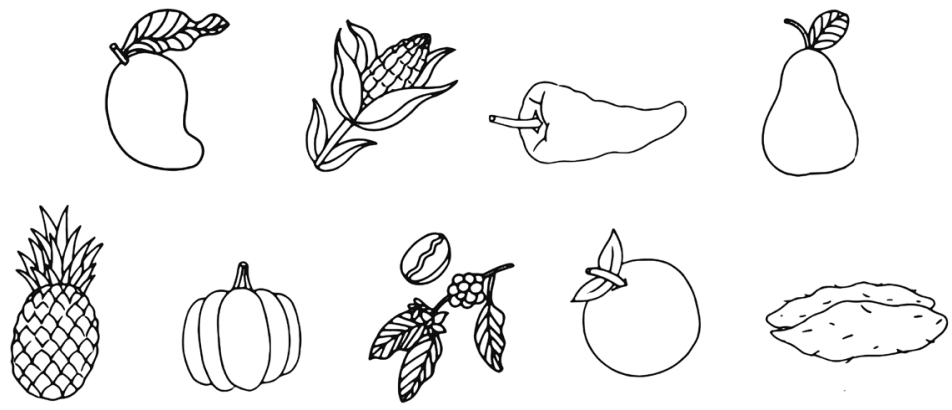

Por ejemplo, para que estas especies germinen se necesitan distintas cantidades de tiempo. Compártelo con ellas:

Rábano 4 a 5 días

Remolacha. 15 a 20 días

Cilantro 7 a 10 días

Zanahoria 12 a 15 días

Coliflor 6 a 7 días

Repollo 5 a 6 días 
Cebolla 8 a 10 días

Perejil 3 a 4 semanas

Apio 15 a 20 días

Cilandro 5 a 7 días

Así como nuestro cuerpo cambia con los años, las plantas crecen, se convierten en árboles, en arbustos, en siembras. Algunos producen comida, otros flores, $y$ todos nos ayudan a transformar el aire que respiramos, y a mantener viva la tierra que habitamos. Nada se mantiene de la misma forma a través del tiempo -ni los cuerpos, ni las montañas-, todo va cambiando a distintas velocidades. Eso es lo que debemos tener claro: cuando las semillas entran a la tierra, inician su transformación. Algunas semillas necesitan pocos días, otras necesitan más. Lo más importante es tener paciencia, porque el camino que lleva a una semilla hasta convertirse en un alimento no es inmediato, y además de paciencia necesita mucha atención.

\section{Hagamos algo juntas}

Somos hermanas de las semillas

El objetivo de esta actividad es reproducir el ciclo de la semilla con movimientos: desde que se deposita en la tierra, hasta que crece, busca la luz, se alimenta de los nutrientes de la tierra, del sol y del agua, le nacen sus frutos, es cosechada, produce nueva semilla y luego regresa a la tierra para continuar con el ciclo de la vida.

Esta actividad consiste en una pequeña coreografía en cuatro movimientos. Para realizarla, le pedirás a las niñas que hagan un círculo, como si fuera un reloj.

Todas juntas harán un ritmo con la palma de las manos sobre sus piernas, o con los pies somatando el piso. Ese ritmo debe ser parecido al paso de las agujas del reloj. Lo que queremos es que se escuche como el paso del tiempo. 
Cada niña tendrá una participación individual. Lo que cada una debe hacer al llegar su turno es lo siguiente:

1. Se pondrán en cuclillas en el piso, acercando su cabeza a sus rodillas (posición fetal).

2. Se pararán y simularán ser una planta, con ramas abiertas, hojas, frutos. Pueden escoger la planta, o el cultivo que más les guste.

3. Harán un movimiento que represente lo que ellas quieren ser cuando sean grandes (una mímica de maestra, doctora, artista, etc.).

4. Volver a la posición inicial, que significa que después de realizar lo que querían, regresarán a la tierra, como las semillas, para continuar con el ciclo de la vida.

No debe dejar de hacerse el ritmo (que será apoyado por un sonido de reloi que enviaremos por WhatsApp). Al final de esta actividad, las niñas tendrán más claro el ciclo de la vida, que podemos ver claramente tanto en las semillas como en nuestra propia vida, es por eso que el baile se llama "Somos hermanas de las semillas".

Explícales más detalladamente este ciclo en los cuerpos, en las estaciones, en los años, en las fases de la luna. Todo en la vida cumple ciclos, todo tiene un inicio y un final, pero siempre se vuelve a empezar. Es la lógica de la naturaleza: morir para hacer posible que nazca más vida. 


\section{Un recipiente para guardar nuestras semillas}

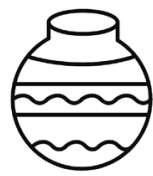

Hacia el final de la sesión, pídeles a las niñas que pregunten en su casa -sobre todo a sus abuelos- si saben alguna historia de las semillas, alguna leyenda o cuento que sepan y que les ayude a comprender más ampliamente lo que aprendieron, pero que también las haga tener un vínculo con su pasado. En su cuadernillo, las niñas tendrán un espacio para anotar las historias que sus familiares les cuenten.

Durante la semana, las niñas platicarán en casa sobre las historias de las semillas. Después de anotarlas en su cuadernillo, encontrarán un espacio para representar esa historia a través de un dibujo. Si no hubiera alguna historia, las niñas podrán dibujar algo de lo que aprendieron en esta sesión. Cada uno de sus dibujos nos servirá en las próximas sesiones para decorar un recipiente en el que podremos guardar nuestras semillas.

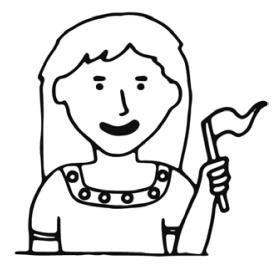




\section{Tercera sesión}

El huerto familiar

Saluda a las niñas. Mientras van llegando, pregúntales qué tal estuvo su semana. Cuando ya estén todas juntas, menciónales la energía que rige ese día según nuestro calendario. Y hablando de tiempo, empieza a preguntarles si se dan cuenta de los cambios que le suceden a la tierra y a la naturaleza con el paso del tiempo. ¿Cómo cambian las siembras según el mes del año, las lluvias y el clima? ¿Cómo se ven los árboles cuando son pequeños?

Diles que, dentro de un tiempo, cada una tendrá un huerto en su casa, y ese huerto crecerá y producirá muchos alimentos que ellas mismas sembrarán y cuidarán.

Recuerda que un huerto familiar es el lugar donde cada familia cultiva hortalizas, verduras, frutas, plantas medicinales, hierbas comestibles y árboles frutales que complementarán su alimentación. También puede ser un lugar para criar aves de corral. Estos huertos deben estar lo más cerca posible de su casa, para asegurar su cuidado y vigilancia.

\section{La tierra no nos cobra por darnos alimentos}

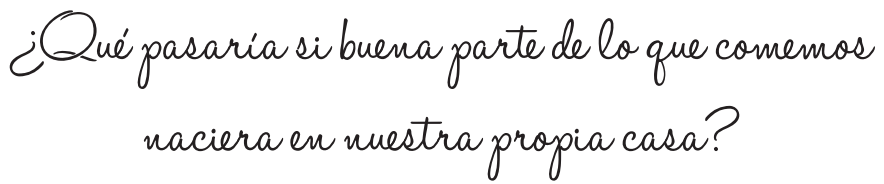

Para conseguir nuestros alimentos casi siempre tenemos que ir al mercado. Muchas veces, el dinero no alcanza y no podemos comprar todo lo que necesitamos. Tampoco sabemos en dónde ha crecido esa comida, y lo más seguro es que para producirla se han utilizado fertilizantes químicos que 
han dañado la tierra y que quedan atrapados adentro de las frutas y verduras que compramos.

Pero, en realidad, la tierra en la que vivimos no ha perdido su capacidad de hacer crecer diversos tipos de comida. Cada una de nosotras puede tener un huerto en su propia casa, en sus patios. Y si los cuidamos bien sabremos que lo que sembramos está sano, podremos tener gran variedad de comidas, y si algo nos falta podremos intercambiarlo con alguna amiga que necesite algo de nuestro huerto.

\section{Recordemos un poco y aprendamos algo más}

Pregúntales a las niñas qué recuerdan de los contenidos que trabajaron durante la primera sesión. Pídeles que definan la diversidad de cultivos. Recuérdales que nada que sea natural, ningún bosque, selva o montaña tiene un solo tipo de árboles o plantaciones. Diles que esa diversidad natural es el modelo que debemos replicar para nuestro huerto, el modelo que la misma naturaleza nos da, porque de esa forma no explotamos la tierra y podemos tener a la mano más variedad de alimentos.

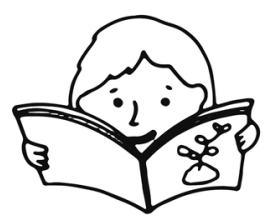

Sigue platicando con ellas, trata de que todas participen, que conversen entre sí. Comparte con todas un concepto que es muy importante: el de soberanía alimentaria. Cuéntales que cuando una variedad de alimentos nace y crece en nuestra propia tierra, podemos variar nuestra alimentación, gastamos menos dinero, podemos intercambiar lo que sembramos, incluso vender alimentos a personas de la comunidad a precios más bajos porque han crecido ahí mismo y no se tuvo que pagar por el traslado. Podemos hacer conservas, salsas, chirmoles, 
refrescos. Incluso pensar en abrir un lugar en donde la gente coma los alimentos de su huerto a precios accesibles. Diles que a eso se refiere la soberanía alimentaria: a la posibilidad de hacernos más independientes con el fruto de nuestro propio trabajo.

\section{Hagamos algo juntas}

\section{La invocación de las especies}

Para esta actividad debes pedirle a las niñas que se organicen en grupos de por lo menos seis integrantes. Cada grupo se denominará Huerto.

Debes poner como muestra un ritmo para que todas lo hagan con las manos, de la siguiente manera:
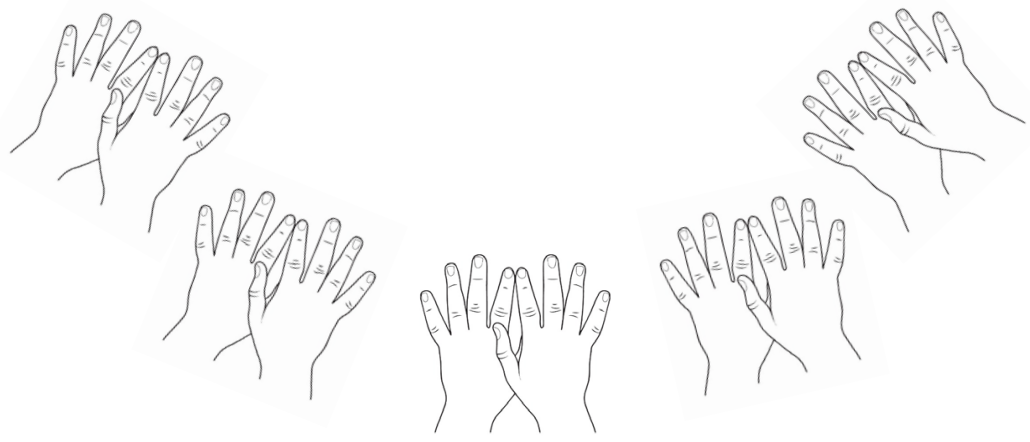

En forma de círculo alrededor de una mesa, una niña empieza a golpear suavemente el piso con las palmas abiertas, de una forma rápida marcando el ritmo, cuatro veces seguidas. La que esté a su izquierda le sigue, y cuando ambas den cuatro palmadas juntas, entra la siguiente. Así una por una, hasta que todo el círculo esté haciendo lo mismo. Este sonido da la idea de reunión (escucha el audio que te llegará por WhatsApp). 
Ahora cambia el ritmo, haciendo dos golpes con los puños sobre una mesa o el piso, y dando un aplauso. (Escuchar el audio como referencia). Con este ritmo empieza el canto:

Vamos a escuchar
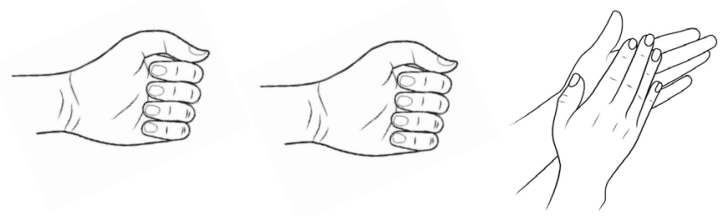

A la tierra hablar
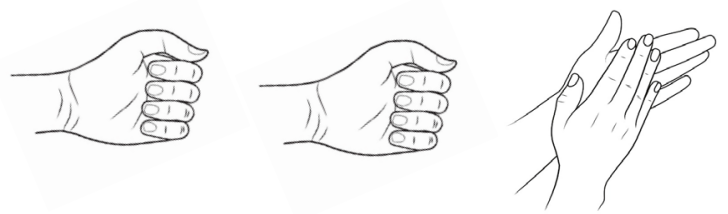

La vamos a curar
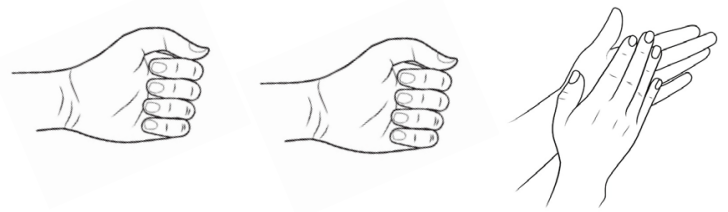

Para poder sembrar (Repetir dos veces)
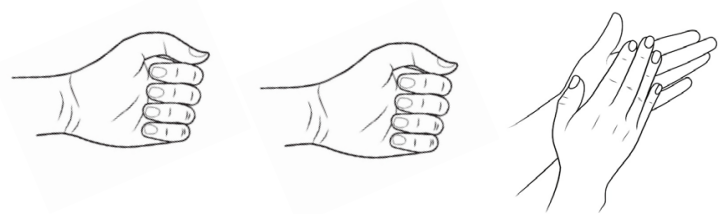
Después de terminar estas dos rondas, se sigue con el mismo ritmo pero ahora cada niña dice el nombre de las hierbas que podría sembrar:

iHierbas!
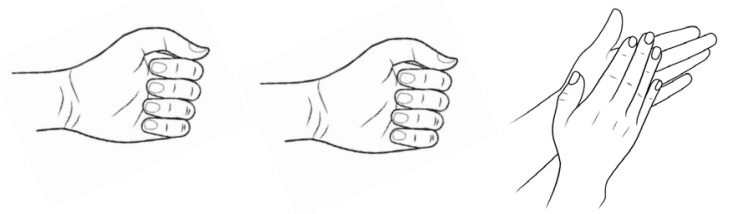

Por ejemplo:

iChipilin!
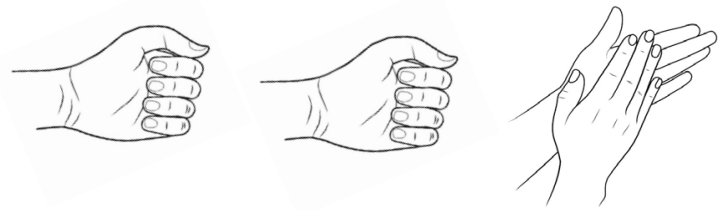

iHierbamora!
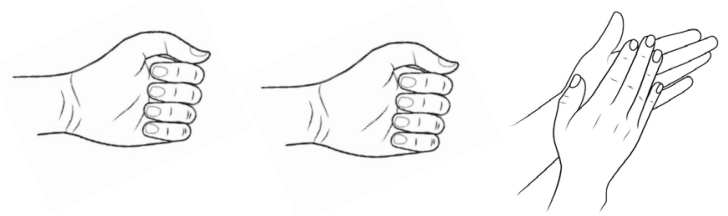

¡Berro!
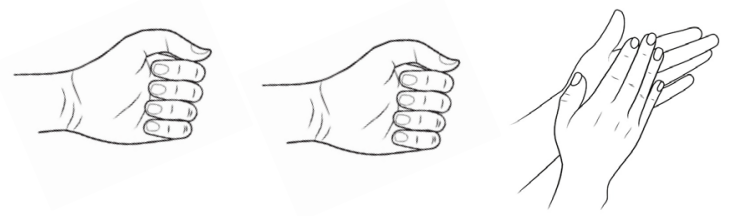
Así, hasta que todas pasen.

Cuando todas hayan dicho una hierba, se debe repetir el canto inicial, y se hace lo mismo con verduras, y luego con frutas.

El objetivo de esta actividad es que las niñas tengan noción de que para tener un huerto familiar es necesario considerar dentro de un plan todas las especies que podrían incluirse.

\section{Planifica tu huerto}

En su cuadernillo, las niñas encontrarán

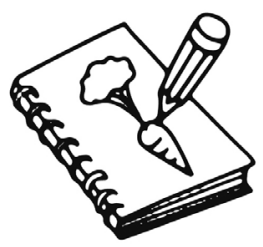
una serie de elementos básicos que deben considerar al iniciar su huerto familiar. Tú deberás reunirlas e irles explicando cada uno de esos elementos, de acuerdo a la información complementaria que te haremos llegar a través de WhatsApp.

Describirás qué es un plan de cultivo, incluyendo las tres dinámicas básicas para concretarlo: la rotación de cultivos, la siembra intercalada y la siembra escalonada.

Les explicarás las características que debe tener el terreno para crear su huerto familiar, y los procesos iniciales que deben desarrollar para prepararlo.

Les contarás detalles de las herramientas básicas que utilizarán durante la creación y mantenimiento de su huerto familiar.

Ellas tendrán toda esta información en su cuadernillo, y a ti te la compartiremos a través de imágenes y audios a tu teléfono celular. 


\section{Imaginemos nuestros huertos}

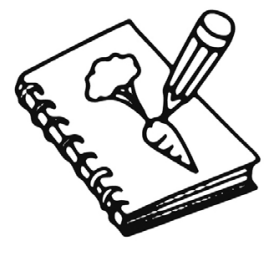

En el cuadernillo de las niñas, habrá un espacio apropiado para que hagan un dibujo. Encontrarán un patio limpio y vacío, y en él deberán dibujar cómo esperan que estén sus huertos dentro de algún tiempo. El cuadernillo espera sus dibujos, así como los patios esperan sus huertos. En este dibujo deberán incluir las diversas especies que sembrarán, llenándolo de color y vida.

Después de las actividades de esta sesión, debes explicarles que hay ciertos cultivos que por el clima o por el tipo de terreno no pueden sembrarse en su comunidad. Por eso, hagan juntas una lista de lo que sí se puede sembrar. Trata de que todas aporten, y apunta las diversas especies en un papelógrafo, para que todas puedan verlo.

Toma en cuenta lo siguiente, y trasládalo a las niñas:

- Lo que cada una va a hacer con su huerto es un acto de vida. Sembrar nos garantiza que seguiremos vivos y que pondremos en práctica un ritual que nuestros padres, abuelos y

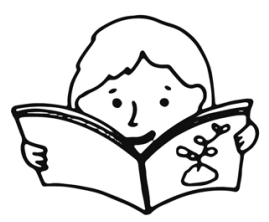
antepasados más lejanos realizaron para garantizar el alimento. Por eso, cuando iniciemos nuestros huertos es importante pedirle permiso a la tierra antes de depositar en ella nuestras semillas. A ella le pediremos que nuestros cultivos sean sanos y abundantes. Además, ofreceremos el fruto de nuestro trabajo a la comunidad a la que pertenecemos, y por eso debe- 
mos agradecerle a la tierra la oportunidad de hablar con ella.

- Revisa las épocas del año y lo que se puede sembrar en ese tiempo, también las fases de la luna y las energías de los días. Cuando vas a sembrar toda la existencia entra en diálogo contigo.

\section{Un recipiente para guardar nuestras semillas}

En el cuadernillo, las niñas encontrarán un espacio para su dibujo de esta semana. En él deben representar a los miembros de su familia, y si es posible, pídeles que consulten con sus padres las costumbres para sembrar. Dichas costumbres también pueden ser parte de ese dibujo. 


\section{Cuarta sesión}

\section{Aprendamos a hablar con la tierra}

Como en las sesiones anteriores, dale a cada una la bienvenida, y cuando todas estén juntas inicia compartiendo con las niñas la energía del día que rige según el calendario maya. Agradéceles por regresar a esta, que es ya la cuarta sesión.

\section{El arte nos acompaña en el proceso}

Lo primero que harás hoy es compartir con las niñas este video. Pídeles que pongan mucha atención y que también sientan lo que la canción y la animación quieren decir.

\section{https://www.youtube.com/watch?v=OQng5VakPS8}

Al terminar de ver y escuchar este video, coméntenlo. ¿Qué les hizo sentir? Pregúntales también cómo les ha ido con su huerto y si se sintieron identificadas con lo que dice la canción.

\section{Mantener nuestro huerto}

Después de esta conversación colectiva, hablarás sobre la tierra en tres etapas:

1. Explícales que la tierra está llena de organismos pequeños y que necesita nutrientes para que lo que sembremos logre salir a la luz y crezca de la mejor manera. Por eso, les darás consejos de cómo mantener su huerto saludable, y sobre cómo deben limpiar la tierra para que los cultivos tengan el camino libre para crecer. 
2. De una forma breve y concisa debes explicarles que la tierra se enferma cuando se le exige que produzca mucho más de lo que tiene capacidad de producir y en tiempos más cortos. Acá puedes usar el ejemplo de las frutas de temporada, que en el pasado solamente se daban en ciertas fechas -como las manzanas o los duraznos-, y que ahora se pueden encontrar en distintas épocas del año. Pero esto no es bueno, porque para que la tierra pueda producirlas la llenan de químicos. Esto no solo enferma a la tierra, sino también a nuestros cuerpos, y con el paso del tiempo la tierra deja de ser buena porque pierde sus nutrientes. Por eso, con los huertos y con nuestra forma de sembrar, estamos curando a la tierra.

3. Es muy importante mantener adecuadamente nuestro huerto, a través del ciclo de riego, de la limpieza constante y de la cosecha en el tiempo adecuado.

Aunque puedes darles instrucciones de cuándo hacerlo, lo más importante es que cada una aprenda a diferenciar cuando la tierra necesita agua, cuando se debe limpiar de maleza y cuando la siembra está lista para ser cosechada. Aunque este es un trabajo que nos enseña a tener paciencia y a percibir el tiempo de otras formas (pues es vida lo que se está formado), también es necesario que día a día trabajemos en nuestros huertos para tener mejores resultados, pero sobre todo para aprender a sentir cómo siente la tierra mientras hace nacer nuestra comida.

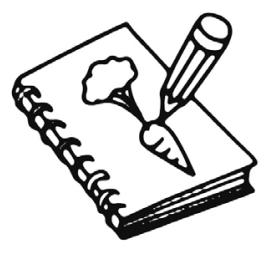

En su cuadernillo, las niñas encontrarán algunas definiciones que les serán útiles. Tienen que ver con los tipos de abono, la constancia de los riegos, y actividades diversas que es necesario conocer para mantener bien nuestro huerto: determinar la humedad de la tierra, en qué consiste el raleo, el desmalezado, la fertilización y 
la cosecha. Repasa con ellas dichas definiciones (que te haremos llegar a través de imágenes por WhatsApp), y hazles preguntas para verificar que dominen los conceptos clave.

\section{Un recipiente para guardar nuestras semillas}

Esta semana, cada una elaborará un dibujo relacionado a lo que los huertos

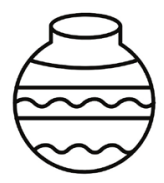
nos hacen sentir. En el espacio indicado en su cuadernillo, podrán dibujarse a sí mismas trabajando en su huerto, pero también pueden tratar de representar en su dibujo lo que sienten cuando están hablando con la tierra.

\section{Investiga, escucha y cuenta}

Es importante que las niñas sepan su historia, que tengan comunicación con sus padres y abuelos para que su comunidad no pierda de vista sus raíces. Por eso, esta semana pídeles que investiguen y pregunten a sus familiares de mayor edad qué saben de la historia de la comunidad, qué han vivido, qué oyeron contar de sus mayores. Cada niña podrá anotar los resultados de su investigación en su cuadernillo. Al iniciar la próxima sesión, compartirán algunos de esos resultados.

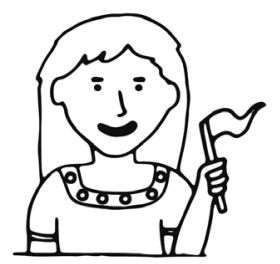




\section{Quinta sesión}

\section{Somos lo que comemos}

Esta es la quinta sesión. Estamos acercándonos al final de este proceso, y por eso es importante que le agradezcas a las niñas su compromiso y su dedicación, ya que todo lo que están haciendo juntas en cada sesión -y luego cada una en sus casas- será importante para que su comunidad sea mejor. Diles que están aprendiendo cosas que son buenas y son útiles para todas. Comparte con ellas la energía del día en nuestro calendario, y trata de relacionar esa energía con lo que han ido aprendiendo.

\section{Hagamos algo juntas}

Ver hacia nuestro interior

En esta actividad es muy importante el silencio. Vas a pedirles que cierren los ojos, pero que tengan muy despiertos todos sus sentidos. Que escuchen, que sientan olores, que respiren profundamente, que vean lo que pasa por su mente en estos momentos.

Después, les pedirás a todas que se imaginen como una planta, un arbusto, un árbol, una hierba o una flor. Cualquier especie que nazca de la tierra y pertenezca al reino vegetal.

Léeles el siguiente texto:

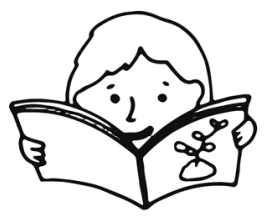

Soy de la tierra. Inicié este camino hace mucho, cuando siendo una semilla pequeñita la tierra me tragó.

Ella, que es tan grande, que es tan buena, me llevó adentro suyo y me dio de comer. Pequeñísimas energías entraban en mí, 
me hacían sentir parte de algo mucho, pero mucho más grande que yo.

Me daba agua, me chineaba entre su oscuridad. Casi sentía que me cantaba para que siguiera con los ojos cerrados.

Con el tiempo, mi piel empezó a cambiar, se hizo más suave y húmeda.

Sentí que tenía que estirarme, moverme lentamente, quizá cambiar de posición.

Así salió de mí una pequeña raíz blanca. Ese día fue muy feliz porque sentía que empezaba a acariciar a mi madre la tierra. Yo le decía 'gracias' con mi pequeña raíz.

Muy pronto nacieron otras raíces.

Ya no era solo una semilla. Estaba cambiando de forma.

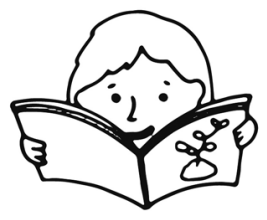

Desde fuera sentí que una voz me llamaba, que me decía: 'Ven hacia mí, avanza'. Y yo sentía que la tierra me decía: 'Sí, ve. Ve con la luz que te está llamando'.

Y así lo hice, porque la luz me llamaba aunque yo no la podía ver.

Me fue creciendo más el cuerpo, ahora no era solo raíz.

Para buscar la luz, una nueva forma me nació: un pequeño tallo que quería ver todo lo que había afuera de mi madre la tierra.

Así, un día, broté. Sentí por primera vez el aire y la luz me dio la bienvenida.

Mi cuerpo siguió creciendo, adentro y afuera de la tierra.

Bebí de la lluvia, bailé con el viento, me alimenté de la luz.

Ahora he crecido. Mi tallo es ancho y me salieron ramas y hojas. 


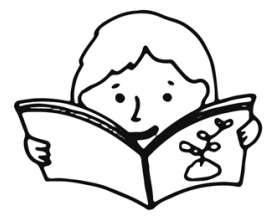

Con ellas abrazo la vida.

Ya no soy una semilla, pero ahora me han nacido a mí muchas pequeñas semillas.

Las lanzo en espera de manos que las tomen por mí, que las pongan en la tierra, para que otra vez ella las cuide en su oscuridad, y las haga crecer hasta que vengan acá, en donde yo estoy ahora, y seamos muchas más, y sigamos bailando con el viento, bebiendo de la lluvia y siempre regresando a la tierra.

Después de un rato en silencio, pídeles que abran los ojos y que respiren lentamente. Ahora una por una contará qué planta se imaginó que era mientras escuchaba el relato. Cuando todas hayan hablado, debes explicarles que ese proceso lleva cada una de las plantas que crecen en sus huertos.

\section{Somos 10 que comemos}

Entrega a cada una de las niñas medio papelógrafo, y pídeles que escriban lo que han comido durante los últimos días. ¿Qué comieron ayer, qué desayunaron hoy? Lo deben hacer de forma individual, aunque no tienen que apuntar sus nombres en el papelógrafo. Pide que dejen los papelógrafos en el suelo, formando un gran círculo.

Todas rodearán el espacio que ocupan los papelógrafos, y deberán ir leyendo lo anotado por sus compañeras. Al finalizar, reflexionen juntas en grupos de tres a partir de las siguientes preguntas. En sus cuadernillos encontrarán un espacio para anotar sus respuestas.

- ¿QQué es lo que más comen las jóvenes de esta comunidad?

- ¿QQué es lo que menos comen? 


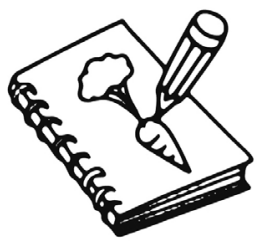

- ¿QQué es lo más accesible que tienen para comer?

- ¿Dónde se producen esos alimentos?

- ¿QQué quisieran comer más, pero no es accesible en la comunidad?

- iTodas comen lo mismo?

- $\dot{L}$ Los alimentos que comen son suficientes para el trabajo y el esfuerzo que realizan cada día?

- ¿QQué sabemos de nutrición en nuestra comunidad?

Al terminar, comparte con ellas la siguiente reflexión:

Nuestra salud y nuestros ánimos para la vida dependen de lo que comemos y la forma en que comemos. Comer no es lo mismo que nutrirse. Cada cuerpo necesita cierto tipo de nutrientes para estar en buenas condiciones y nutrirse de diferentes alimentos para aprovechar toda la riqueza que tiene la tierra.

En tu WhatsApp recibirás información importante que deberás compartir con las niñas, respecto a la Olla Nutricional. En base a esa información, discutan en grupo qué es necesario comer para cuidar bien nuestros cuerpos y por qué todas y todos merecen comer bien.

\section{Un recipiente para guardar nuestras semillas}

En el espacio indicado que aparece en sus cuadernillos, pídeles a las niñas que

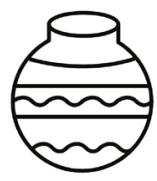
pinten un plato de comida que incluya algunos alimentos que están creciendo en su huerto. Es necesario que imaginen cómo se verá ya servido en un plato todo lo que ahora mismo está creciendo en cada una de sus casas. Procura que ten- 
gan crayones de muchos colores. Debajo de este espacio, encontrarán una serie de pequeños cuadros en blanco. Las niñas deben llenar cada uno de ellos con cada uno de los colores que acaban de usar. Platiquen entre ustedes respecto a la cantidad y variedad de colores utilizados. Explícales que esos colores serán importantes en la próxima sesión, ya que los utilizarán en la elaboración de sus recipientes para guardar sus semillas.

Si los colores son pocos, debes explicarles que no es lo más adecuado que nuestra comida tenga pocos colores, porque eso significa que no estamos teniendo una comida balanceada, con los nutrientes que su cuerpo necesita. Sucede lo mismo con la tierra: mientras más colores tenga, más variedad de cultivos están creciendo en ella.

\section{Para la próxima sesión}

Pídele a las niñas que durante la semana continúen investigando y preguntando a los adultos de su casa sobre cómo era la comunidad antes de que ellas nacieran. Puedes sugerirles que hagan preguntas como estas: ¿̇qué se comía antes?, ¿̇cómo se preparaban los alimentos? , ¿cómo se servían las comidas?, ¿̇qué cosas han cambiado?, ¿̇se sigue sembrando de la misma manera? Anotarán sus respuestas en el espacio indicado en sus cuadernillos.

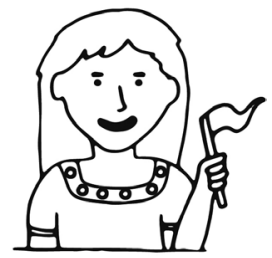




\section{Sexta sesión}

\section{Imagino lo que seré}

Están acercándose al final de estas sesiones. Ahora tú conoces a las niñas mucho mejor y has podido ver en ellas el potencial que tienen. Esto es importante que lo tengas presente ahora que dirigirás una sesión que tiene que ver con el futuro. Debes ayudarlas a que cada una pueda ver de forma clara la proyección que tenga de sí misma.

Pero, además del ejercicio personal que cada una debe hacer para poder trazar su camino, debes ponerlas en contexto: aprender a ver su comunidad, no solo en el presente sino también su historia, lo que necesita para mejorar, las cosas que ellas quisieran ver diferentes en su espacio de todos los días. El desarrollo no debe verse solo como un logro personal, sino como el resultado de la vida en comunidad. Explícales lo valiosas que son ellas para que las cosas buenas pasen en el lugar en que viven.

\section{Hagamos algo juntas}

Yo dibujo mi camino

Pídele a las niñas que se ubiquen en un espacio amplio. Puede ser un patio o un salón. Diles que se paren y que empiecen a caminar, que se muevan por todo el espacio, que se crucen con sus compañeras, que se sientan parte del lugar que ahora mismo comparten. Diles que mientras caminen, respiren despacio y pongan atención a las preguntas que harás. Que traten de ir pensando sus respuestas, mientras caminan por el lugar:

¿Qué es lo que más te gusta hacer?

¿Te gusta imaginar cosas?

¿Te gusta escuchar a la gente? 
¿Te gusta el deporte?

¿Te gusta bailar?

¿Te gusta cantar?

$\dot{\imath} T$ e gusta enseñar?

¿Te gusta cocinar?

¿Te gusta sembrar?

$\dot{2} T$ e gusta ver las estrellas?

¿Te gusta pensar?

¿̇Te gustan los números?

¿Te gusta escribir?

¿Te gusta pintar?

¿Te gusta saber cómo era el pasado?

¿Te gusta usar las manos para construir algo?

¿Te gusta observar las plantas?

¿̇e gustan los animales?

$\dot{2}$ Te gusta organizar a tus amigas para hacer cosas juntas?

¿Te gusta curar a las personas?

$\dot{2}$ Te gusta combinar colores?

¿Te gusta viajar?

¿Te gusta vender y comprar?

¿Te gusta hacer tu ropa?

¿Qué te hace feliz?

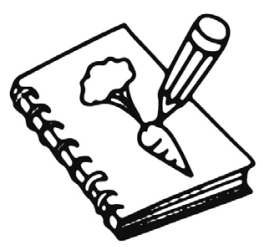

Pídeles que se detengan y que anoten en sus cuadernillos alguna de las reflexiones que hicieron mientras caminaban y tú les hacías esas preguntas. Pídeles que traten de visualizarse en el futuro: ¿̇Qué estarán haciendo? ¿̇Que quisieran ser? ¿QQué les haría felices?

Luego, pídeles que se ubiquen en un círculo. Diles que en esta búsqueda es importante tener claro que lo que más disfrutamos en la vida, lo que verdaderamente nos hace sentir felices, se puede convertir en nuestra profesión, en nuestro modo de vida. 
Ahora cada una dirá las cosas que más disfrutan hacer. $Y$ cuando cada una lo haga, tú deberás preguntarle a todas: ¿Qué podemos hacer para ayudar a nuestra compañera a cumplir sus sueños? ¿ Cómo podemos aportar para que ella sea feliz? Todas deberán participar contándonos algo de su reflexión.

En el transcurso de la conversación, quizá debas guiarlas y sugerirles algunas profesiones pueden buscar, según lo que les apasiona, según lo que más les gusta. Para tener la mayor cantidad posible de opciones, ponemos a tu disposición esta lista de profesiones:

$\begin{array}{cc}\text { Psicóloga } & \text { Ingeniera } \\ \text { Arquitecta } & \text { Doctora } \\ \text { Antropóloga } & \text { Astrónoma } \\ \text { Escultora } & \text { Maestra } \\ \text { Bailarina } & \text { Pintora } \\ \text { Economista } & \text { Constructora } \\ \text { Comerciante } & \text { Futbolista } \\ \text { Cocinera } & \text { Transportista } \\ \text { Agrónoma } & \text { Trabajadora Social } \\ \text { Deportista } & \text { Servidora pública } \\ \text { Cantante } & \text { Enfermera } \\ \text { Escritora } & \text { Guía turística } \\ \text { Bióloga } & \text { Tejedora } \\ \text { Veterinaria } & \end{array}$

\section{Lo que puedo hacer con mi conocimiento}

Al concluir este ejercicio que ayudará a las niñas a identificar su vocación, es muy importante darles a entender que la formación de cada una es sumamente valiosa a nivel personal, pero también a nivel colectivo. Mientras más felices sean haciendo lo que hacen, más claramente podrán ver las formas en que habrán de colaborar con su comunidad. 
Por eso, ahora debes preguntarles cómo ven el estado de las cosas en su entorno. ¿Qué creen que está bien, qué hace falta, cómo les gustaría que fuera su comunidad?

Ahora que tienen más claro lo que quieren ser cuando sean grandes, pregúntales cómo a través de su profesión pueden colaborar para que su comunidad sea mejor.

En su cuadernillo, cada niña encontrará una lista de preguntas y un marcador con tres caritas. Una feliz, una seria y una triste. Si la respuesta es positiva, deberán pintar la cara feliz. Si las cosas no son del todo buenas, deberán pintar la cara seria. Y si la situación es muy mala, deberán pintar la cara triste. Esto nos ayudará a tener más claro cómo son las condiciones de vida en nuestra comunidad, y en qué tenemos que concentrarnos para mejorarlas.
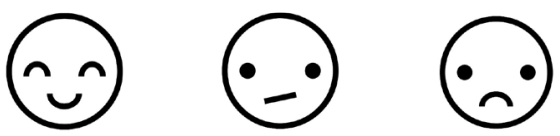

- ¿̇Hay luz en todas las casas?

- ¿̇Todas las niñas y niños van a la escuela?

- ¿Hay instituto básico en la comunidad?

- ¿̇Hay institutos de diversificado en la comunidad?

- ¿̇Hay diversidad de cultivos?

- íTodos pueden comprar su comida en el mercado?

- ¿̇Hay acceso a agua potable?

- ¿Está limpio el municipio?

- íLa gente está conforme con los COCODES (autoridades)?

- ¿̇Se sienten inseguras? 
- ¿̇hay espacios para la recreación?

- iHay espacios para convivir y dialogar?

- ¿̇Hay hospital o centro de salud?

- ¿̇Es fácil obtener medicinas?

- ¿Hay bosques cercanos?

- ¿́La gente sabe su idioma materno?

- íTodos saben leer y escribir?

Al contar el número de caritas que marcaron, podrán ver cuál es la situación de su comunidad. Esto es importante para la siguiente actividad.

\section{Mi comunidad puede estar mejor}

Durante algunas semanas, las niñas se han acercado a sus familiares para averiguar distintas cosas. Han preguntado por el pasado y por las costumbres que han ido cambiando. Recuérdales todo este proceso y pídeles que mencionen las cosas que han escuchado del pasado, las cosas que eran diferentes.

Coloca un papelógrafo en un lugar visible y divídelo en dos columnas. En la primera columna escribe lo que las niñas vayan mencionando respecto al estado actual de la comunidad. Y en la segunda columna, anota los cambios que esperan provocar para que su comunidad sea mejor en el futuro. En esta parte es importante mencionar lo que se necesita para que esto pase, y relacionar estas necesidades con las caritas que marcaron en la actividad anterior.

Al principio de las sesiones se habló mucho de las semillas. Ahora las niñas comprenden de forma más clara toda la vida que una semilla puede desarrollar. Guía una conversación en la cual ellas puedan compararse con las semillas. Diles que ellas también pueden hacer crecer su imaginación, sus ideas, sus ganas de trabajar y contribuir con cosas buenas. Pueden sembrar cambios para su comunidad, los 
cuales crecerán con la misma paciencia y dedicación que le han puesto a su huerto familiar.

Cada una de ellas puede ser maestra, psicóloga, arquitecta, cantante, contadora de historias, socióloga, doctora. Hablen sobre todas las posibilidades del futuro, y léeles el siguiente texto:

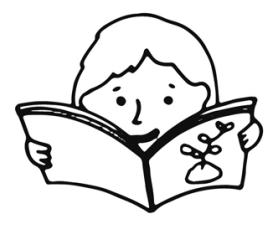

Ustedes son semillas y guardan muchas posibilidades, que pueden crecer, multiplicarse y alimentar a su comunidad. Así como han trabajado en su huerto para que produzca alimento, así tienen que trabajar en ustedes mismas, para que todo eso que llevan dentro crezca y se multiplique. Su vida puede convertirse en un huerto lleno de vida y posibilidades.

\section{Un recipiente para guardar nuestras semillas}

Las niñas deberán revisar su cuadernillo. En cada sesión, hay una parte que lle-

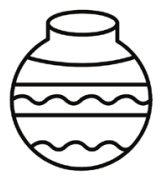
va por título 'Un recipiente para guardar nuestras semillas'. En ellas hay dibujos, colores, historias. Todo eso será útil en estos últimos días para concretar un proyecto que resume la experiencia de estas sesiones.

Diles que traten de recordar las historias, los dibujos que han hecho durante las últimas semanas. Y dales un recipiente. Puede ser una vasija de barro (que será decorada con témperas) o un pequeño recipiente plástico (que podría decorarse con dibujos hechos con crayones sobre papel bond, recortados y pegados en la superficie exterior del recipiente). 
Explícales que su recipiente debe contar una historia -la historia de lo que aprendieron, la historia de lo que sembraron, la historia de su comunidad-a partir de algunos de los dibujos y que han elaborado en este tiempo. Dichos dibujos se ubicarán en la superficie exterior del recipiente. Muéstrales como ejemplo una vasija maya antigua, para darles una idea y también para enseñarles que esa era la forma en que nuestros abuelos guardaban sus historias.

\section{Para la siguiente sesión}

Pídeles que dediquen tiempo a pensar qué dibujos plasmarán en su recipiente, y que traten de hacer los bocetos 0 pruebas que sean necesarias. $\mathrm{Si}$ es posible, diles que adelanten pintando y decorando sus propias vasijas. Como cada uno de esos recipientes contará una historia, cada niña debe tener clara la historia que quiere contar. Eso le será muy útil cuando sea el momento de presentar los resultados de este proceso a la comunidad. En la última sesión se hará una exposición de la vasija o recipiente que cada una de ellas ha creado. Dales ideas creativas para que cada una piense en su forma de exponerla. Sugiéreles el uso de pino, flores, frutas, o incluso alguna cosecha de su huerto que nos puedan compartir. Luego, estas vasijas serán el recipiente en el que podrán guardar las semillas que sembrarán en su huerto familiar.

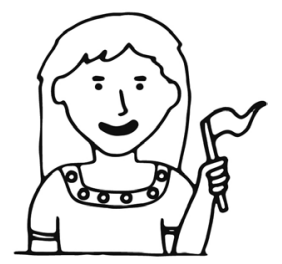




\section{Séptima sesión}

\section{Un regalo para mi comunidad}

Este camino de siete semanas se ha convertido en una forma de conocerse unas a otras y de conocerse a sí mismas. Ahora han iniciado un huerto, han preguntado por el pasado, han buscado adentro de sí mismas su vocación, han aprendido a ver de diferentes formas a su comunidad, han imaginado el futuro, han aprendido a contar su historia con palabras, formas y colores.

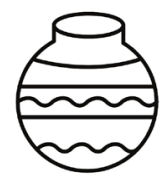

Ahora deben hacer una reunión final, para cerrar el proceso que han iniciado y para presentar sus resultados a la comunidad. Para eso, un poco antes de la hora en que hayan definido la presentación comunitaria de sus vasijas, reúnete con las niñas para hablar muy brevemente sobre el proceso y sobre el camino que trazaron en su vasija - desde su pasado, su comida, su familia, hasta la forma en la que se imaginan en el futuro.

En la vasija estará representado el regalo que cada niña hace a su comunidad, porque además de haber hecho crecer la vida en sus huertos, además de hablar con la tierra y de comprender los tiempos que son necesarios para que todo se regenere, cambie y dé frutos, ahora también pueden pensarse ellas como parte esencial del lugar al que pertenecen. Ser una niña es muy importante, y su forma de aprender, de hacer crecer la vida y de cuidarla es una parte esencial de su ser. Ahora deben pensar en todo lo que su huerto traerá, en la memoria de sus antepasados y en todo el futuro que, como las semillas, está esperando para brotar de ellas mismas. 
Al finalizar pídeles que cada quien arregle su pequeño espacio para la presentación de su vasija. Cuando la gente de la comunidad llegue, la exposición deberá estar montada de acuerdo a los materiales de apoyo que te haremos llegar por WhatsApp. Entonces, la gente de la comunidad irá pasando por los espacios de cada niña, que deberá contar lo que aprendieron y lo que su vasija representa para la historia de ellas, y también para la historia de su comunidad.

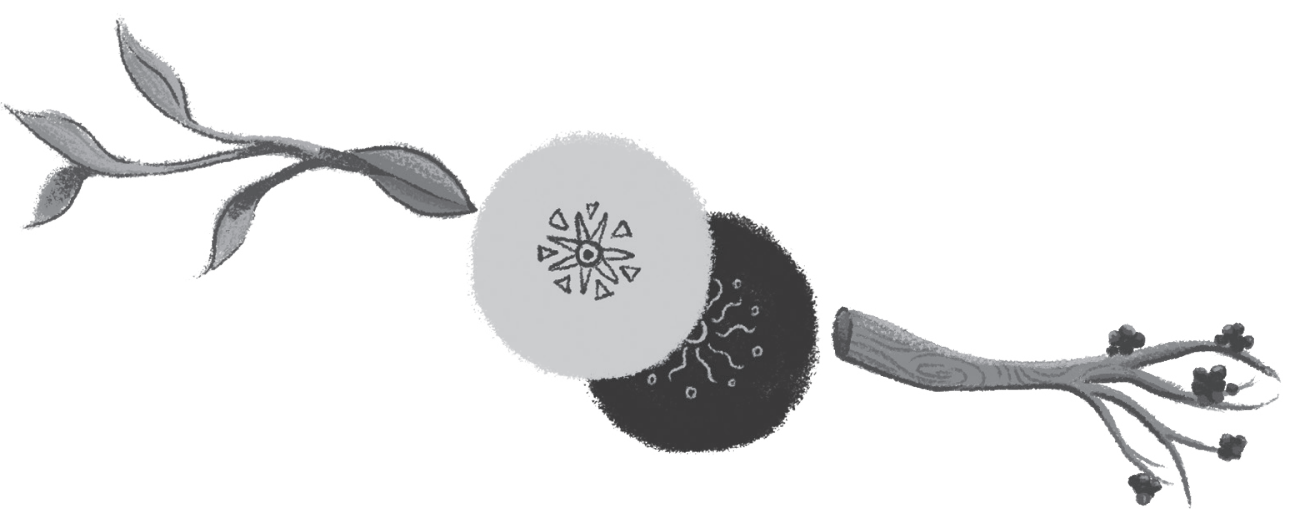

\section{Canciones}

\section{$\mathrm{y}$ contenidos de apojo}

Los siguientes enlaces pueden servirte en cualquiera de las sesiones, para reforzar el contenido que compartirás con las niñas:

Canción "Maltyox", de Ishto Juevez. Es sobre las semillas y la diversidad de la vida. Nombra los colores que identifican a las cuatro esquinas del universo en la cosmovisión maya. https://www.youtube.com/watch? $v=m i 2$ VfrvL9Y 
Canción: "Los ingredientes", de Ishto Juevez. Habla de los ingredientes que componen nuestras comidas, ayuda a comprender que todo es parte de un ecosistema y que para que ese ecosistema esté bien aprovechado es necesario cumplir ciclos.

https://www.youtube.com/watch? $v=$ mi2VgfrvL9Y

Canción: "Jardinera", de Rita Indiana. Se describe un huerto urbano en patios y terrazas. Con ella las niñas pueden comprender que se trata de hacerle espacio a la vida y a los cultivos en nuestros espacios y que la vida puede crecer aunque no tenga un terreno grande.

https://www.youtube.com/watch? $v=g K 87$ ekqlJ2I

Semillas Nativas y Criollas de Guatemala (Senacri) es una organización que tiene más de una década produciendo semillas, implementando huertos y compartiendo formas de resguardo y producción de alimentos. Permanentemente dan talleres y espacios de formación con personas especializadas.

https://www.facebook.com/senacri

Alticultura es una organización que busca soluciones para la adaptación al cambio climático. Manejan formas innovadoras de sembrar y pueden otorgar mucha información desde distintos lugares del país.

https://www.facebook.com/Alticultura

Cuento "El coleccionista de semillas". Con este cuento las niñas van a aprender sobre la paciencia que deben tener con sus semillas y sus huertos, y sobre todo la ternura y dedicación que deben ponerle a sus cultivos.

https://www.youtube.com/watch? $v=e$ DimwrJ7jnU

Canción y video educativo "Siembra". Además de la canción que habla del sentido vital de la siembra, este es un ejemplo perfecto de lo que se puede generar cuando se unen el arte, la educación y la regeneración de la vida a través de la siembra. https://www.youtube.com/watch?v=OQng5VakPS8 


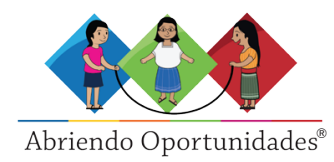

